\title{
Evaluation de l'éducation pour la santé chez des jeunes gens suisses
}

\section{K. Biener}

Institut de Médecine Sociale et Préventive de l'Université de Zurich

\section{Résumé 1}

En différentes études nous avons examiné l'effet d'une éducation de santé à court terme (durant deux leçons), à moyen terme (durant un an) et à long terme (trois ans) chez les jeunes gens suisses. Nous avons obtenu de meilleurs résultats après l'influence à long terme, par exemple concernant les habitudes de fumer, qu'après l'influence à court terme.

${ }^{1}$ Le texte intégral en langue allemande paraitra dans le no 6/1977 de cette Revue. 